\title{
A configuração visual em edições brasileiras de obras da literatura gótica
}

\author{
Visual configuration in Brazilian editions of gothic literature books
}

Letícia Lima de Barros, Manoel Deisson Xenofonte Araújo

\begin{abstract}
Análise comparativa, composição gráfica, design editorial
O presente trabalho adota como objetivo evidenciar as particularidades relacionadas à composição gráfica de obras da literatura gótica em edições brasileiras. A investigação se deu através de uma análise quantitativa realizada a partir de um checklist, que comporta elementos referentes à tipografia, layout e imagem. O procedimento partiu da seleção de cinco títulos do supracitado estilo literário e, de acordo com a disponibilidade permitida pela coleta do material, determinou-se três recortes de tempo - 1970 a 1989 , 1990 a 2009 e 2010 a 2019 - para alocação dos exemplares. Assim, encaixou-se cada obra em um dos intervalos, totalizando quinze exemplares destinados à investigação. Como resultado, verificou-se que a maior parte das edições não possui um arranjo visual específico que denote o gênero literário da obra.
\end{abstract}

Comparative analysis, graphic composition, editorial design

This paper aims to highlight the particularities related to the graphic composition of gothic literature novels in Brazilian editions. The research took place through a quantitative analysis carried out from a checklist, which includes typography, layout and image as components. The chosen books included five gothic literature texts and three time periods - 1970 to 1989, 1990 to 2009, and 2010 to 2019 - were selected for the classification. Thus, each work was fitted into one of the time clippings, totaling fifteen copies to the research. As result, we found out that most editions don't have a specific visual arrangement that shows the literary genre which the book belongs to.

\section{Introdução}

O presente estudo adota como objetivo central a identificação e a análise comparativa de componentes tipográficos, pictóricos e esquemáticos de publicações da literatura gótica editadas no Brasil. Para isso, selecionou-se edições a partir de intervalos de tempo predeterminados, de modo a favorecer a comparação entre impressos publicados em períodos distintos; evidenciou-se as particularidades de cada exemplar a partir de fichas elaboradas para coleta de dados das publicações e, por fim, expôs-se as informações levantadas, considerando semelhanças e diferenças em relação à presença dos componentes nas diferentes edições.

A delimitação do tema contido nesta pesquisa foi realizada no intuito de expor a relação existente entre o conteúdo presente nas obras analisadas e sua composição visual, de modo a identificar as consonâncias entre tais aspectos. Dentro do contexto, também objetivou-se trazer à tona pontos como a possível existência de componentes gráficos diferenciadores das

Anais do $10^{\circ} \mathrm{CIDI}$ e $10^{\circ} \mathrm{CONGIC}$

Kelli C.A.S. Smythe, Rafael de Castro Andrade (orgs.)

Sociedade Brasileira de Design da Informação - SBDI

Curitiba | Brasil | 2021
Proceedings of the $10^{\text {th }} \mathrm{CIDI}$ and $10^{\text {th }}$ CONGIC

Kelli C.A.S. Smythe, Rafael de Castro Andrade (orgs.)

Sociedade Brasileira de Design da Informação - SBDI Curitiba | Brazil | 2021 
publicações em relação a dos demais gêneros literários, elementos que permaneceram ao longo do tempo ou que caíram em desuso e a probabilidade do resgate de determinados recursos estilísticos.

\section{O processo de seleção das obras e construção da ferramenta avaliativa}

Estudo de caso foi o procedimento selecionado para aplicação no trabalho, estruturado em uma pesquisa quantitativa de análise documental, destinada à identificação de elementos comuns entre os livros góticos selecionados. Dessa maneira, construiu-se um checklist portando componentes objetivos voltados para tipografia, figuras, elementos esquemáticos e configuração do livro (elementos pré-textuais, pós-textuais, suportes), considerando miolo e capa. A pesquisa se deu nas fases 1) exploratória, destinada à busca do material a ser investigado e 2) analítica, voltada ao desenvolvimento da ferramenta de análise gráfica e sua aplicação aos livros coletados na etapa anterior.

\section{Fase exploratória}

Considerando os títulos da Literatura Gótica, fez-se uma listagem contemplando obras abraçadas pelo estilo. A partir dessa lista, realizou-se o processo de busca dos exemplares em meios físicos e virtuais. Nesse ponto, visualizou-se a primeira filtragem durante a verificação da disponibilidade dos livros nos locais de venda. A partir disso, delimitou-se uma primeira lista das publicações destinadas à análise.

Com a lista e os exemplares encontrados na busca, delimitou-se um intervalo de tempo para inclusão das obras. Para isso, destacou-se, inicialmente, o livro de publicação mais antiga até o mais recente, buscando encaixar os demais exemplares dentro do recorte temporal. Identificando os anos recorrentes nas obras, verificou-se que seria possível elencar o material encontrado em três blocos: 1970 a 1989, 1990 a 2009 e 2010 a 2019. Após a filtragem, as obras localizadas e selecionadas foram: Drácula, de Bram Stoker; Histórias Extraordinárias, de Edgar Allan Poe; Noite na Taverna, de Álvares de Azevedo; O Morro dos Ventos Uivantes, de Emily Brontë e O Retrato de Dorian Gray, de Oscar Wilde.

A maior parte dessas obras possui uma especificidade dentro do gênero literário ao qual pertence. Drácula surge como representante do Horror Gótico, que consiste na atmosfera de inquietação gerada pelo gótico associada à repulsa proveniente do horror; Histórias Extraordinárias, além de tratar do gótico e do horror, possui contos que originaram o Romance Policial. Noite na Taverna é representante da Prosa Gótica, a segunda geração do Romantismo no Brasil, enquanto O Retrato de Dorian Gray abriga o Gótico Decadentista, sendo atribuição do Gótico a atmosfera medieval e a assombração do passado no presente, ficando a cargo do Decadentismo a postura do personagem, que busca sensações novas, portando um anseio de libertação. 


\section{Fase analítica}

Os tópicos seguintes abordarão especificações e classificações utilizadas para os elementos integrantes do checklist, recurso utilizado no processo de análise dos exemplares coletados. Subdividem-se nos blocos de tipografia, Linguagem Gráfica Verbal, elementos intrínsecos e extrínsecos, imagem, cor, grid e layout, contando, também, com desdobramentos dentro de cada bloco.

\section{Tipografia}

Para a classificação dos tipos, utilizou-se as nomenclaturas definidas por Ambrose e Harris (2011), que subdividem as tipografias entre tipos Góticos, Romanos, Grotescos, Escriturais e Gráficos, e de Clair e Busic-Snyder (2009), que consideram as Letras Negras, Estilo Antigo, Estilo Moderno, serifa quadrada e em bloco, Sans Serif, Script, Cursiva, Display e Decorativo. Considerou-se, também, a especificação de serifas e caracteres grotescos apresentada por Ambrose e Harris (2011). Desse modo, selecionou-se as nomenclaturas Letras Negras, Serifadas (subdivididas em Estilo Antigo, Transicionais, Modernas, Egípcias, Clarendon e Typewriter; a forma da serifa recebe as especificações: abaulada, apoiada, não-apoiada, quadrada apoiada, aguda e em filete), Sem Serifa (com as variações Grotesca, Neogrotescas, Geométrica, Humanística, Quadrada e Arredondada), Script, Cursiva e Display/Decorativa.

\section{Linguagem Gráfica Verbal}

O conceito apresentado por Michael Twyman (1982) propõe a relação entre o conteúdo informacional e sua apresentação visual. Para isso, o autor apresenta um modelo contendo classificações para principais formas de organização da linguagem gráfica, incluindo a forma linear pura (linha de texto sem interrupções), linear interrompido (quebra do texto ao final da linha), lista, linear ramificado (apresentação textual em subníveis), matriz (texto em formato de tabela), não-linear direcionado (presença de elemento de destaque que influi na linearidade da leitura) e não-linear (ritmo de leitura interrompido, mas sem elemento de destaque). Essas categorias descrevem as interrupções na linearidade da leitura e foram utilizadas no checklist em uma abordagem direcionada à mancha tipográfica. 
Tabela 1: Características da linguagem gráfica através de combinações de configuração (eixo x) e modo (eixo y). Adaptado de Twyman (1982).

\begin{tabular}{lllllll}
\hline & $\begin{array}{l}\text { Linear } \\
\text { puro }\end{array}$ & $\begin{array}{l}\text { Linear } \\
\text { interrompido }\end{array}$ & $\begin{array}{l}\text { Lista } \\
\text { ramificado }\end{array}$ & $\begin{array}{l}\text { Matriz } \\
\text { rano-linear }\end{array}$ & $\begin{array}{l}\text { Não- } \\
\text { direcionado }\end{array}$ & linear \\
\hline Numérico & & & & \\
verbal & & & & \\
Pictórico e & & & \\
numérico & & & \\
verbal & & & \\
Pictórico & & & \\
Esquemático & & & & \\
\hline
\end{tabular}

\section{Elementos intrínsecos e extrínsecos}

Ainda com base em Twyman (1982), tem-se um modelo que distingue elementos intrínsecos (inclui características presentes nos próprios tipos, como bold, itálico, versalete e tamanho) e extrínsecos (referente ao conjunto de caracteres e possibilidades de mudanças em suas configurações, como cor e espaçamento). Para o checklist, elencou-se, como elementos intrínsecos: peso (com as subdivisões extralight, light, regular, bold e extrabold), caixa (alta, baixa, alta/baixa e versalete), ênfase (itálico e sublinhado), tamanho e capitular. Nos componentes extrínsecos, tem-se recuo, colunas, entrelinha, alinhamento (à esquerda, à direita, justificado e centralizado) e fólio (inferior simétrico, inferior assimétrico, superior simétrico, superior assimétrico, inferior centralizado e lateral centralizado).

Não se encontrou especificações direcionadas especificamente ao elemento fólio, diferentemente dos integrantes anteriores. Diante disso, elencou-se variáveis para o componente a partir de elementos observados nas obras de Ambrose e Harris (2009a, 2012) para que sua categorização pudesse ser efetuada.

Imagem

A seção pictórica do checklist foi construída a partir da obra de Joly (2007). Em uma análise imagética, Joly pontua os tipos de mensagens constituintes (plástica, icônica e linguística). Dentro da mensagem plástica, atribui variáveis como suporte, moldura e composição. $\mathrm{O}$ item composição diz respeito ao trajeto realizado pelos olhos na leitura imagética, dividida em: construção focalizada (linhas direcionadas a um ponto específico), construção axial (objeto situado no centro do olhar), construção em profundidade (a estrutura se apresenta em perspectiva, considerando um elemento em primeiro plano) e construção sequencial (o olhar percorre a página até recair sobre o objeto). No checklist, o bloco referente à imagem utiliza as especificações apresentadas por Joly para a composição, acrescidas de componentes voltados ao enquadramento, ângulo e cores.

No enquadramento, utilizou-se, como classificações, plano geral (representação ampla do cenário), plano de conjunto (exibe boa parte da cena, mas possui mais espaço para a figura 
humana), plano médio (apresenta o indivíduo de corpo inteiro) e plano americano (representação humana do joelho para cima). O meio primeiro plano oferece enquadramento da cabeça à cintura e o primeiro plano toma a área do peito acima, enquanto o primeiríssimo plano comporta a região da cabeça aos ombros e o plano detalhe foca em objetos pequenos ou partes do corpo. Em relação à altura dos ângulos, normal equivale ao nível do olhar da pessoa retratada, plongeé indica o nível acima dos olhos, ao passo que o contra-plongeé indica o nível abaixo dos olhos.

Cor

O sentido de cor utilizado dentro do checklist volta-se ao papel de comunicação não verbal desse elemento, capaz de evocar reações de acordo com o entendimento dos indivíduos e as normas culturais vigentes em meios sociais (FRASER \& BANKS, 2007).

A partir disso, considerando que determinados tons podem ser tratados de modo parecido em culturas distintas, pode-se ponderar sobre um significado intrínseco ou coletivo para certas cores (FRASER \& BANKS, 2007). A cor comunica e pode associar-se às referências pessoais que evidenciam decisões tomadas ao lidar com tonalidades, também incluindo a assimilação e preceitos sociais do uso dos tons. Para o bloco cor do checklist, utilizou-se as especificações frias, quentes, neutras e duotone, buscando entrar em concordância com as incidências observadas nas edições coletadas para análise.

\section{Grid}

A introdução do grid no checklist considerou aspectos como as áreas ativas e passivas do design, em função do caminho percorrido pelo olhar na leitura da página. A partir disso, tem-se a existência de áreas centrais, pontos que podem ser utilizados para acomodar as principais peças da composição, simultaneamente à decisão de deixar outras partes menos visíveis, assim chegando às classificações simétrica, assimétrica, composta ou de módulos para o grid (AMBROSE \& HARRIS, 2009a):

Figura 1: Grid simétrico, assimétrico, em módulos e composto (com colunas e módulos), respectivamente. Fonte: Ambrose e Harris (2009a).

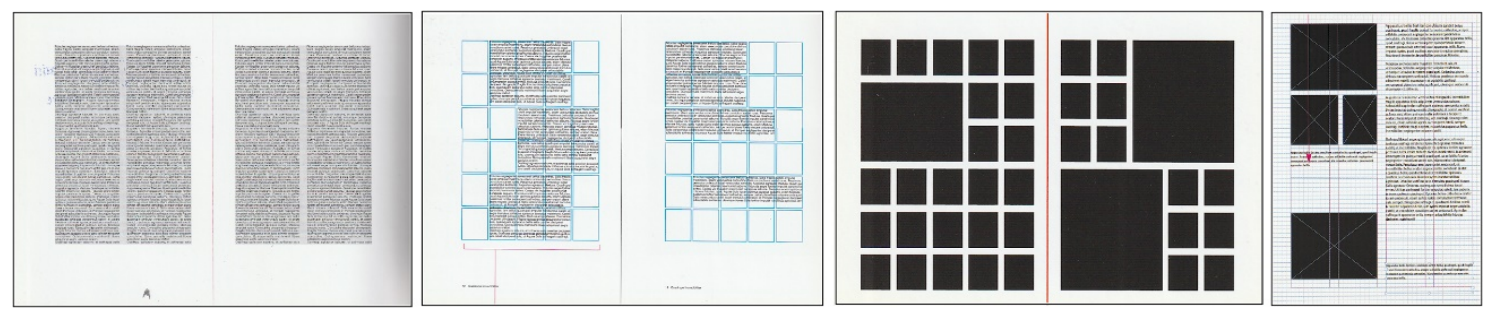


O checklist também considera as especificações voltadas à organização de elementos entre si e em relação à página. Essa disposição influi na recepção do conteúdo, podendo auxiliar ou dificultar o acesso à informação (AMBROSE \& HARRIS, 2012). Considerando tais pontos, chegou-se à classificação intitulada como direcionamento de leitura, portando as subdivisões: vertical, horizontal e diagonal. $O$ item foi inserido no bloco de tipografia, dado o formato das publicações analisadas - dotadas de um volume textual mais largo -, complementando o campo da mancha tipográfica.

Layout

Por fim, no bloco layout, alocou-se os itens referentes à composição do livro, considerados por Haluch (2013) e complementados por aspectos apresentados em Fonseca (2008). Na parte pré-textual do livro, tem-se: falsa folha de rosto, folha de rosto, página de créditos, dedicatória, epígrafe, sumário, prefácio e agradecimentos. Para o corpo do texto, selecionou-se os elementos adornos (dividido em cabeçalho, fios e floreio/fundo de lâmpada) e margens. Por fim, a parte pós-textual é constituída por posfácio, apêndice, glossário, índice, colofão e errata. A seleção de tais elementos considerou, também, a incidência dos componentes nos materiais coletados.

Para os elementos relativos ao acabamento do livro, elegeu-se os itens marcador, folha de guarda, orelhas, sobrecapa, encadernação (subdividida em capa dura - que compreende as classificações costura lateral e costura em sela -, lombada quadrada, canoa e espiral), lombada (nas suas variações francesa e americana) e dimensões. A costura lateral é diferenciada por atar os cadernos paralelamente à lombada - não favorece a abertura completa do livro -, e a costura em sela une os cadernos com fios através da linha de dobra da lateral - aqui, o miolo consegue atingir abertura plana (FONSECA, 2008). A lombada quadrada conta com a aplicação de cola em uma das laterais das folhas para fixação no dorso, enquanto a canoa faz uso de grampos.

\section{Formato do checklist}

O modelo de checklist desenvolvido tomou como referência formatos já utilizados em outras fichas de pesquisas voltadas à análise gráfica. A primeira delas é o modelo utilizado para investigação da memória do Jornal Posição (DUTRA \& FONSECA, 2014). Também se adotou como referência o formulário elaborado por Carvalho (2018), empregado no estudo gráfico de cadernos do jornal O Povo e, como última referência, há o checklist desenvolvido no projeto Memória Gráfica da Comunicação Impressa do Cariri da Universidade Federal do Cariri, produzido com o intuito de delimitar uma identidade cultural nos impressos efêmeros da região: 
Figura 2: Parte da FREGT - Ficha de Registro dos Elementos Gráficos e Técnicos. Possui orientação verticalizada e botões assinaláveis. Fonte: Dutra e Fonseca (2014).

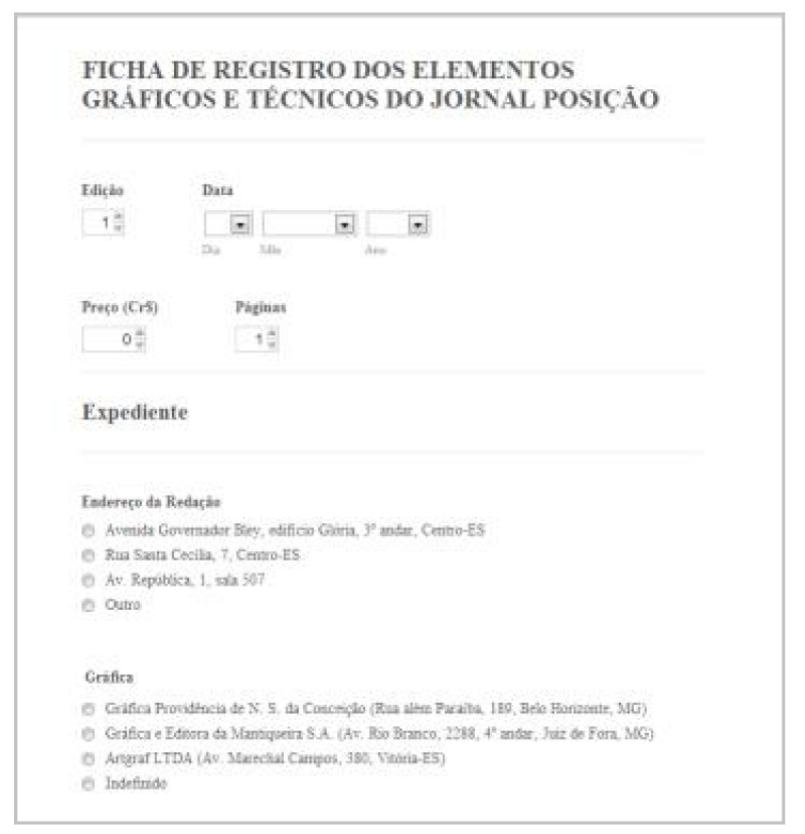

Figura 3: Trecho da ficha de análise produzida por Carvalho (2018): incorpora caixas de seleção e cabeçalho para identificação das edições.

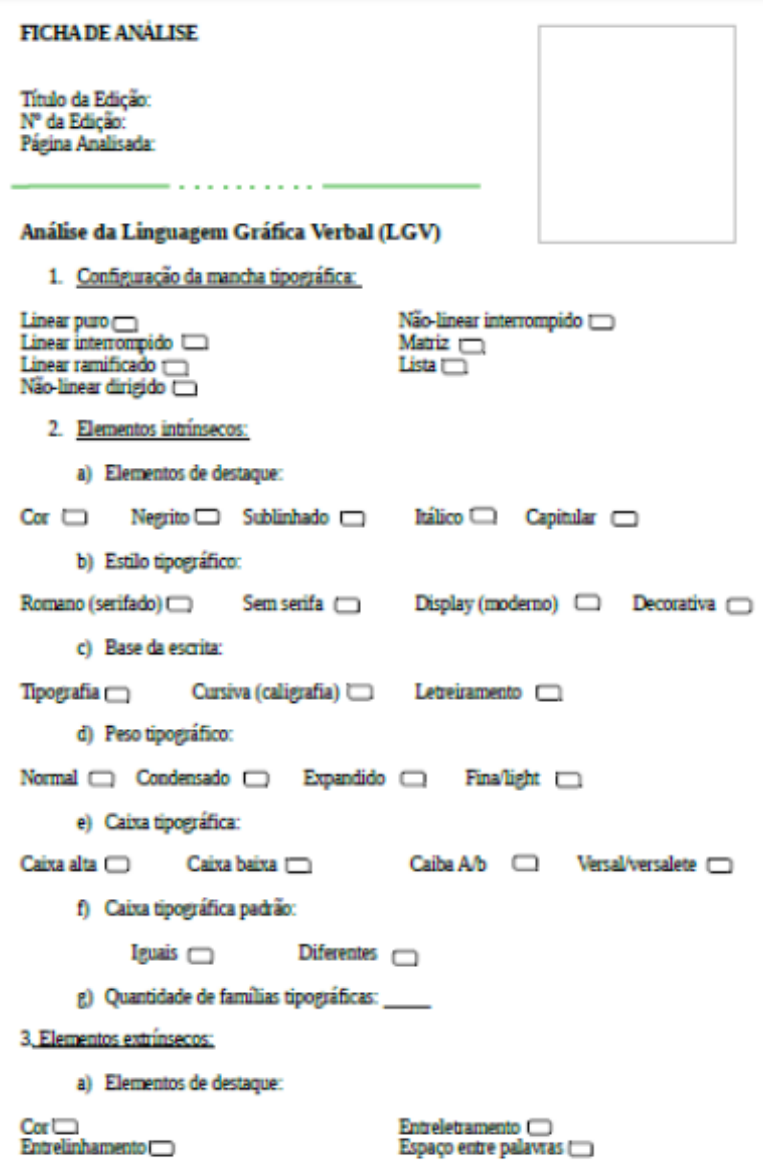


Figura 4: Ficha de análise gráfica feita para o projeto Memória Gráfica. Organiza os desdobramentos das variáveis de modo retilíneo, também valendo-se de caixas para seleção. Fonte: Barros et al. (2018)

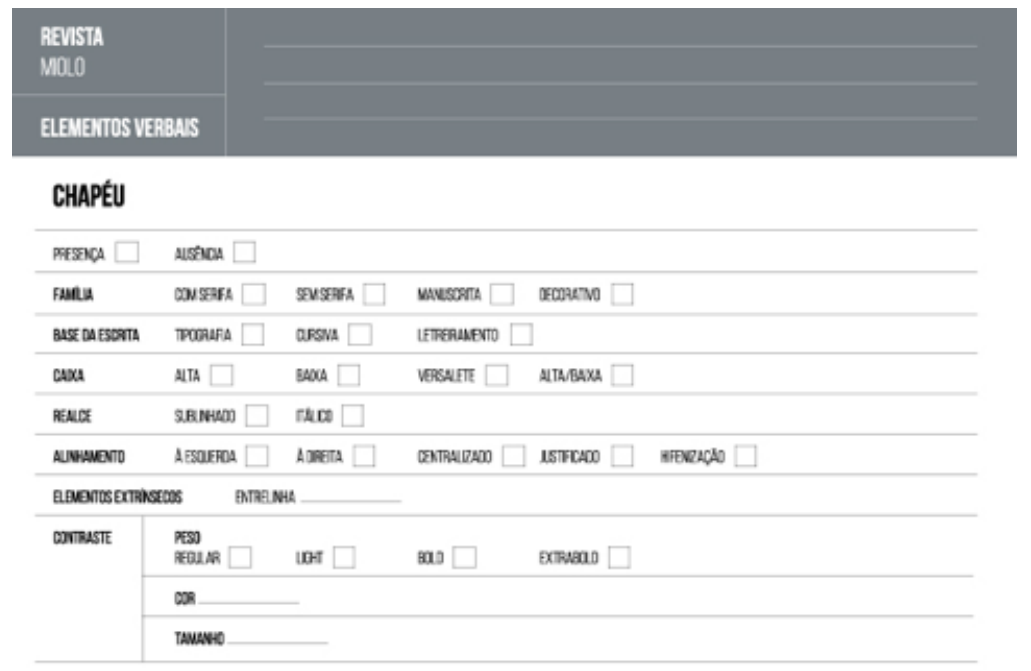

Associando as referências listadas às variáveis selecionadas para a análise, fez-se uma modelo para a ficha em orientação horizontal, atentando-se para o modo de organização dos elementos junto às suas subdivisões. Pensou-se como tais itens poderiam ser acomodados e compreendidos com mais clareza, e, para isso, as alternativas aplicadas incluem o estabelecimento de um nível hierárquico através do tamanho e peso do texto, assim como o uso da variação de cores, somando um total de 14 páginas:

Figura 5: Primeira página do checklist desenvolvido para a análise. Fonte: Os autores da pesquisa.

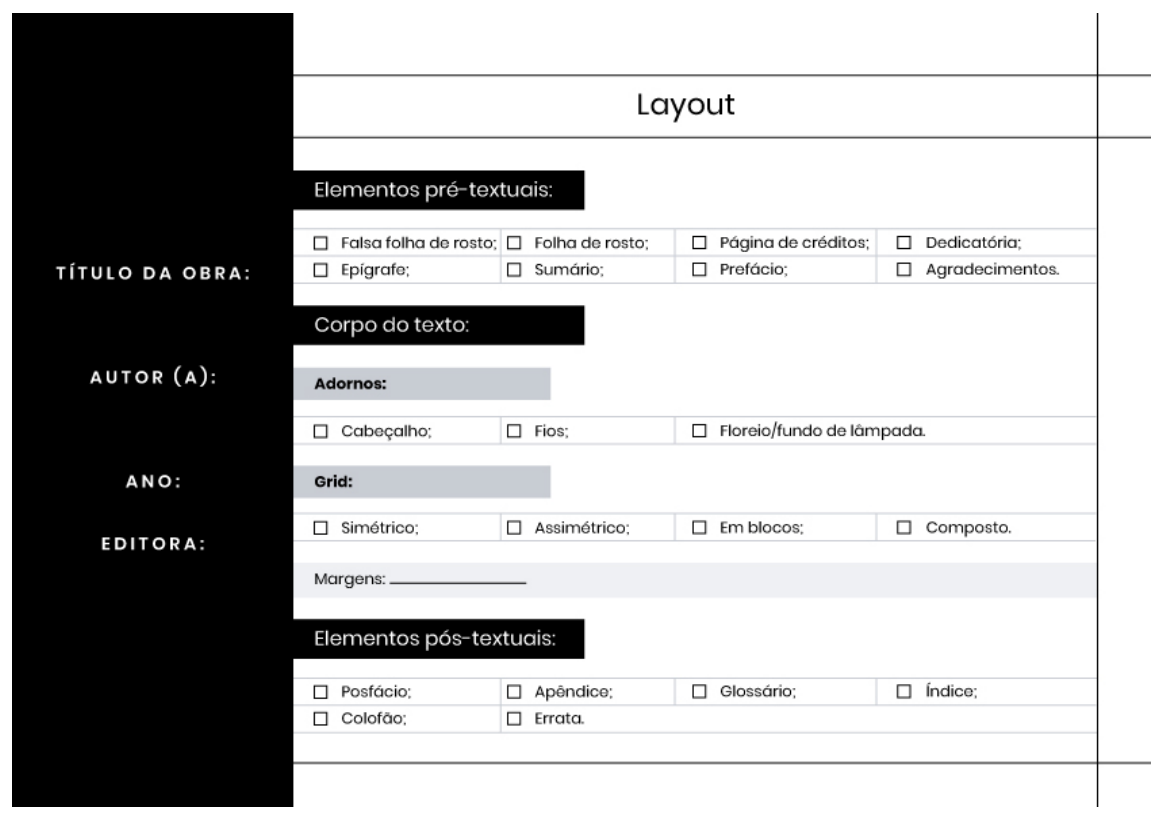

O checklist possui 3 macro divisões (layout, tipografia e imagem), segmentados em tipografia do corpo do texto, de títulos de capítulos e da capa, imagem do miolo e da capa e, ao final, uma subdivisão voltada para capas sem imagens, incluindo opções para sua composição 
(moldura, fios, cantoneiras e repetição/padrão). Ao final de cada bloco, há um box reservado para observações, no intuito de tornar a análise mais precisa mediante os possíveis pormenores contidos nas obras.

\section{Resultados e discussões}

Para esse trabalho, serão apresentados os resultados organizados de uma maneira geral ${ }^{1}$, considerando todas as 15 edições coletadas. Encaixados dentro dos intervalos, tem-se as edições de Drácula (1985, 2002, 2014), Histórias Extraordinárias (1988, 1998, 2010), Noite na Taverna $(1973,2002,2016)$, O Morro dos Ventos Uivantes $(1971,1995,2014)$ e O Retrato de Dorian Gray $(1980,1999,2010)$.

Figura 6: Capas dos exemplares de Drácula coletados na análise (1985, 2002 e 2014, respectivamente). Fonte: Acervo pessoal

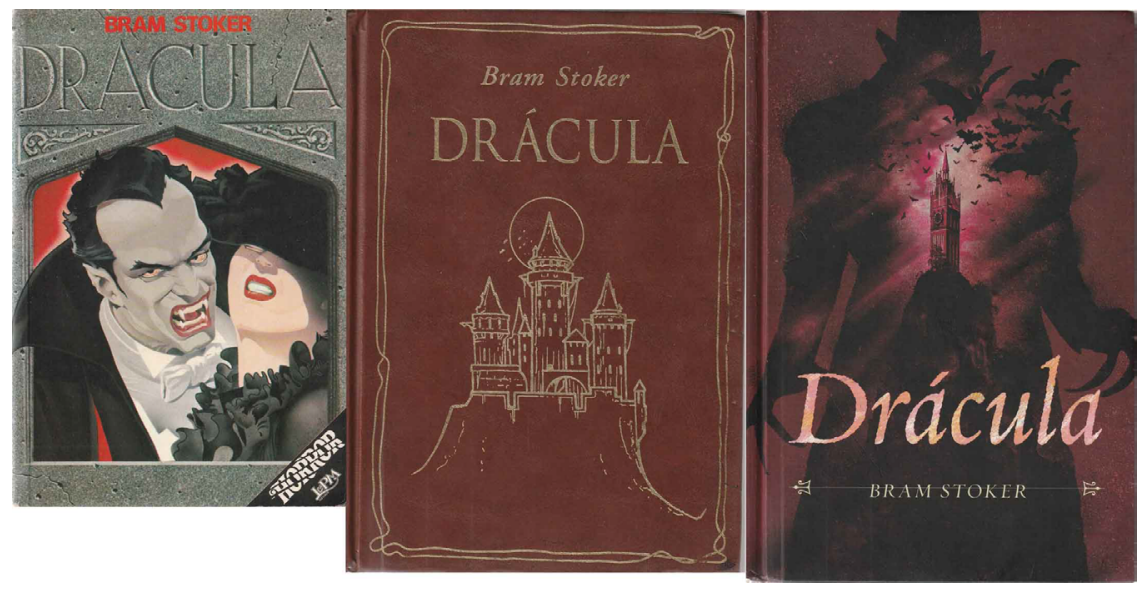

Figura 7: Capas dos exemplares de Histórias Extraordinárias coletados na análise (1988, 1998 e 2010, respectivamente). Fonte: Acervo pessoal.
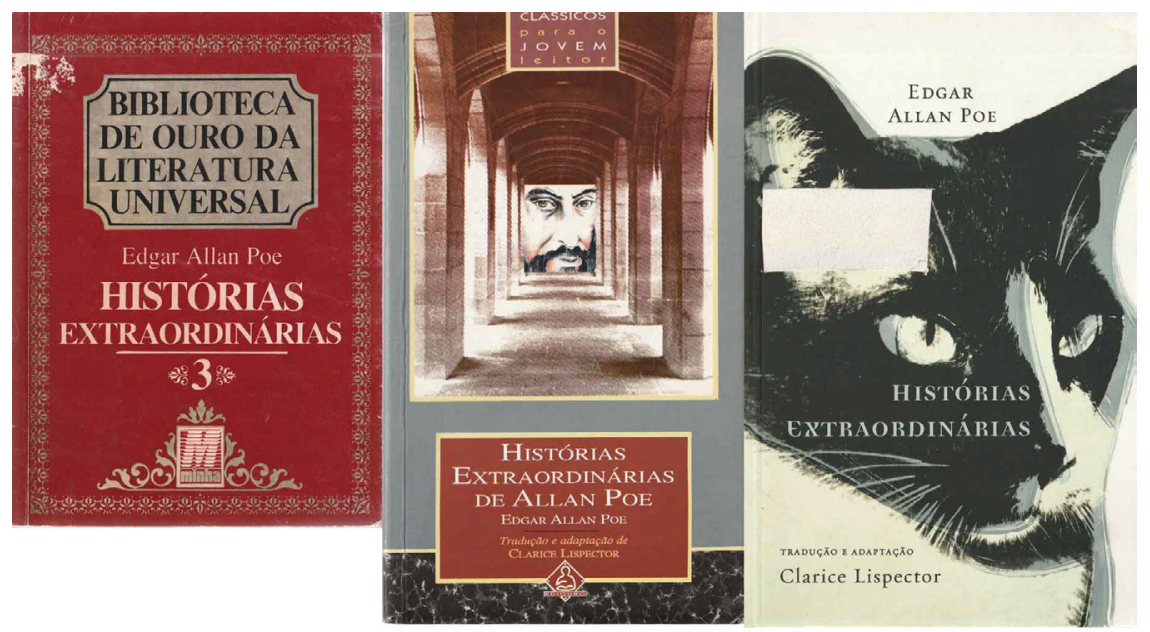

\footnotetext{
${ }^{1}$ Originalmente, organizou-se os resultados de três maneiras: 1) em relação a cada um dos três recortes, 2) em função de cada obra e 3) considerando a totalidade de exemplares coletados. Aqui, optou-se pela exposição das informações coletadas através da terceira forma, dada a extensão do trabalho.
} 
Figura 8: Capas dos exemplares de Noite na Taverna coletados na análise (2016, 2002 e 1973, respectivamente). Fonte: Acervo pessoal.

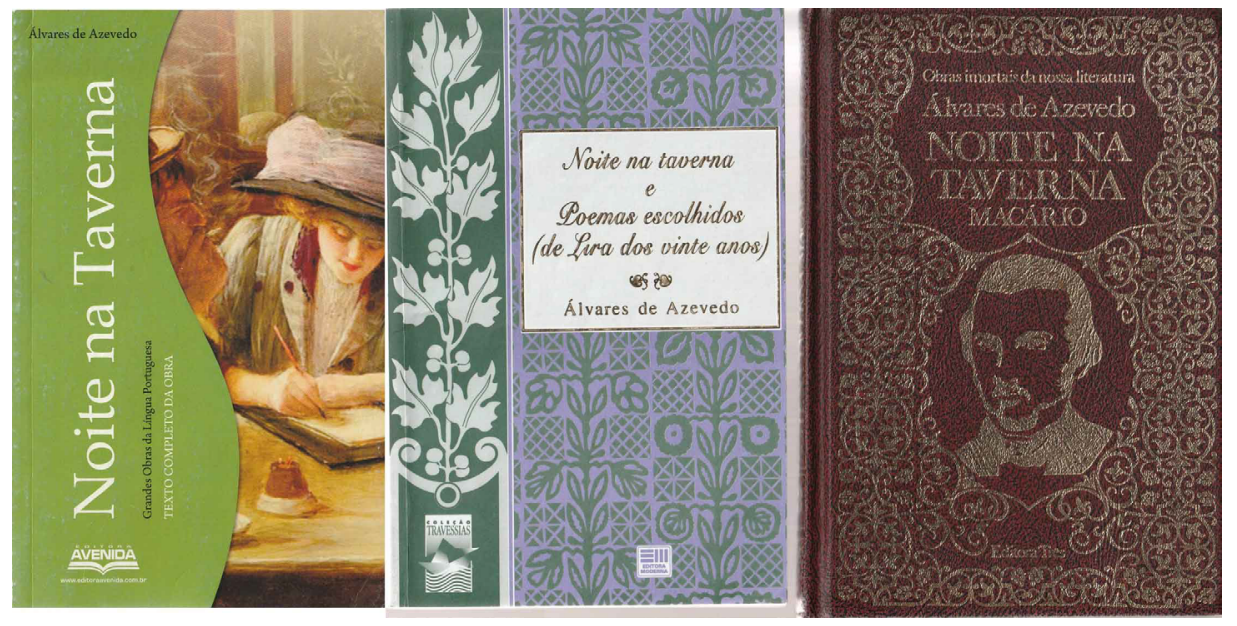

Figura 9: Capas dos exemplares de O Morro dos Ventos Uivantes coletados na análise (2014, 1995 e 1971, respectivamente). Fonte: Acervo pessoal.

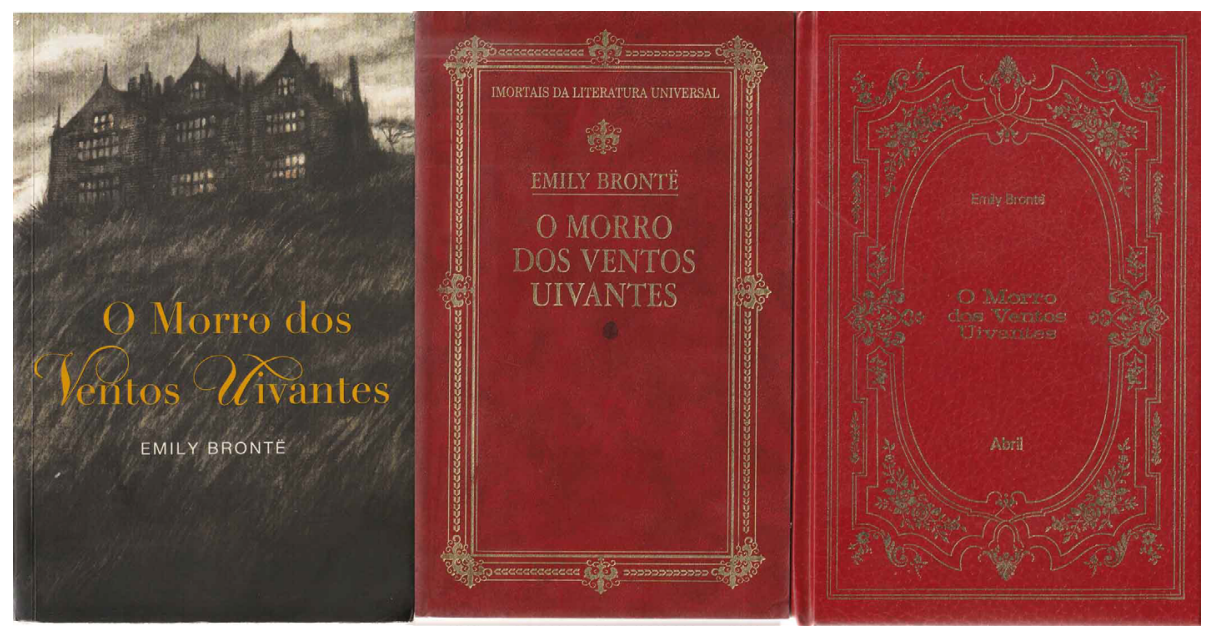

Figura 10: Capas dos exemplares de O Retrato de Dorian Gray coletados na análise (1980, 1999 e 2010, respectivamente). Fonte: Acervo pessoal.
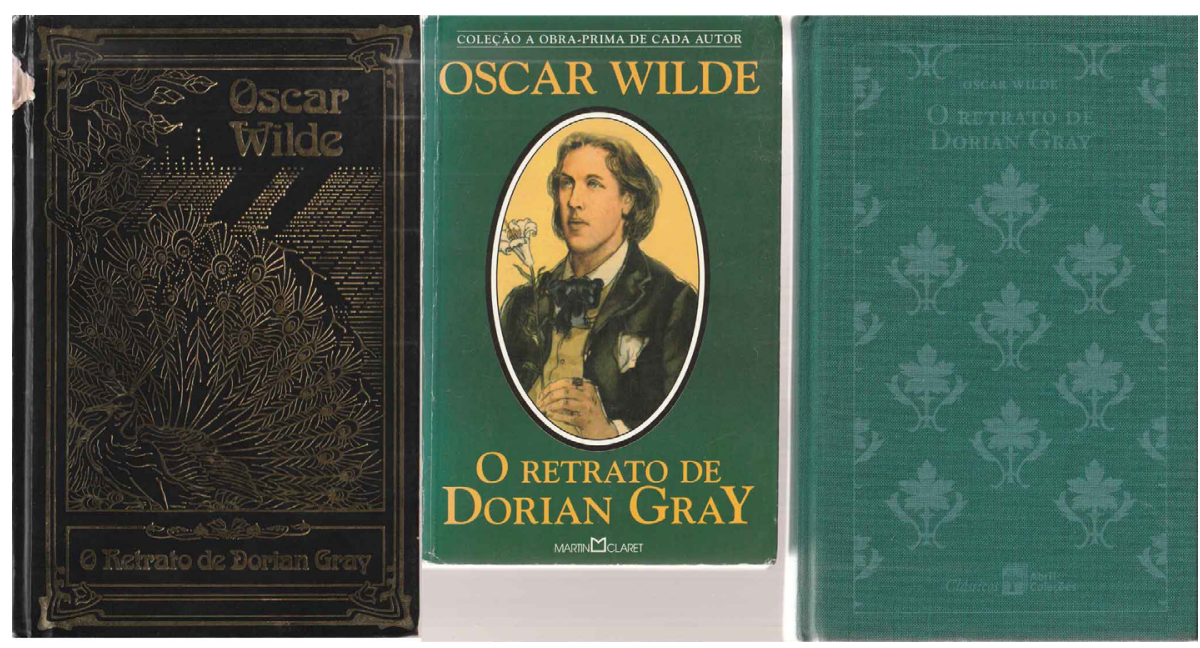
No bloco layout, como pontos comuns a todos os exemplares, estão os elementos folha de rosto, página de créditos e grid em sua variação simétrica. Os demais componentes exibem variações para a incidência de elementos como falsa folha de rosto, dedicatória, epígrafe, sumário e prefácio. Como adorno, identificou-se a maior presença de fios e floreios. Dentre os componentes pós-textuais, o colofão obteve maior presença (somando 06 incidências). Nos elementos externos, a folha de guarda revelou-se como o item mais repetitivo. A encadernação em lombada quadrada foi maioria, seguida pela capa dura com costura em sela; além desses, nenhum outro tipo de encadernação foi identificado. Finalizando o bloco, houve um empate entre as variantes de lombada americana e francesa. Um dos livros fugiu a essa regra, dispondo seus elementos textuais de modo vertical em vez de horizontal, fugindo da classificação adotada para o componente.

Em relação à tipografia do corpo textual, em sua maioria, verificou-se uma combinação de características referentes ao Estilo Antigo e às Transicionais; Consequentemente, a maior parte da forma das serifas foi apoiada. Todos os impressos apresentam mancha tipográfica linear interrompida, sentido de leitura vertical, alinhamento justificado, peso regular e caixa alta/baixa, sendo 12 deles detentores de ênfase itálica em determinados pontos do texto. $O$ fólio exibiu variações em sua localização: esteve na posição inferior simétrica, na superior simétrica, inferior centralizada e lateral centralizada.

Figura 11: Lombada com texto em disposição verticalizada e exemplo de tipografia serifada visualizada no miolo do objeto de estudo. Fonte: Acervo pessoal.
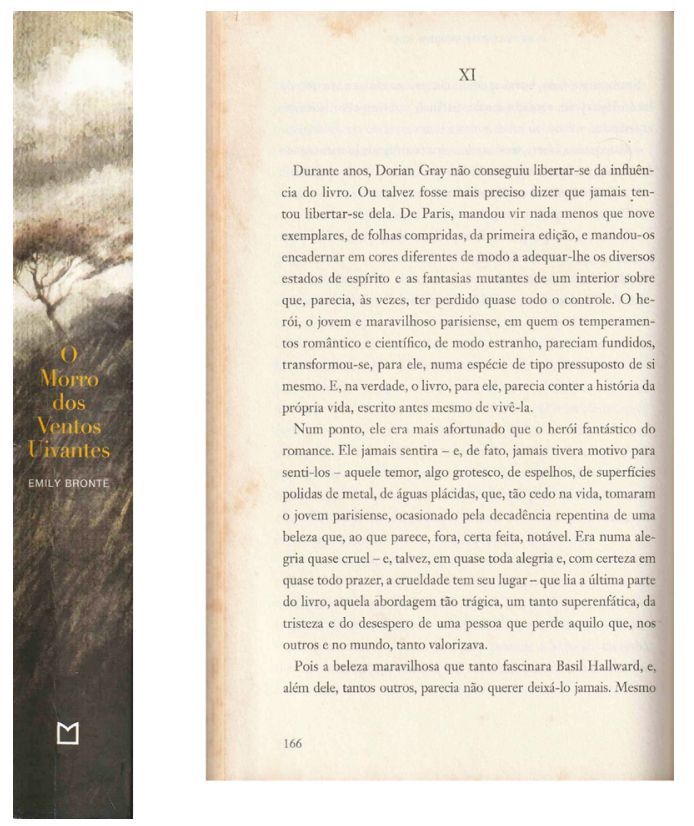

A tipografia dos títulos dos capítulos se mostrou mais diversa do que a empregada no corpo do texto. Embora a maior incidência também tenha correspondido às Transicionais, as Modernas e Clarendon ampliaram sua participação, incluindo uma aplicação do tipo Display. Assim sendo, a maior parte das serifas verificadas possui forma apoiada (somando 10 das publicações). O peso se dividiu em regular e bold e a caixa alta obteve maior ocorrência 
(presente em 10 exemplares). No alinhamento, o modo centralizado possui maior uso, somando 12 presenças.

$\mathrm{Na}$ capa, considerando apenas o título da obra, houve um equilíbrio maior entre as classificações Estilo Antigo, Transicional e Moderna, e, numa proporção menor, os tipos Script, Cursivo e Display. Assim como nos casos anteriores, as serifas apoiadas foram mais presentes, somando 10 incidências. A maior parte das tipografias adere ao peso regular (11 ocorrências); a caixa alta/baixa é a mais presente, incluída em 07 das publicações, seguida de perto pela caixa alta, com 06 aparições. O título centralizado é o mais comum, empregado em 13 dos impressos.

Das imagens presentes no miolo, verificou-se moldura em sua maioria. Voltando-se ao enquadramento, as aplicações foram distribuídas nas classificações plano de conjunto, americano, meio primeiro plano, primeiro plano, primeiríssimo plano, detalhe e médio. A altura do ângulo normal e o duotone são especificações comuns a todas as figuras observadas; o lado $3 / 4$ foi o mais utilizado e a composição dividiu-se, majoritariamente, em construção focalizada e axial.

As imagens da capa, por sua vez, receberam moldura em 06 casos e todas apresentam altura de ângulo normal. Por outro lado, possuem variações quanto ao enquadramento nas classificações planos de conjunto, médio, geral, americano meio primeiro plano e primeiríssimo plano. O lado dividiu-se nas especificações $3 / 4$, frontal e de perfil; a construção, por sua vez, definiu-se nas formas axial, em profundidade e sequencial. Dentre as cores, as quentes ocuparam mais espaço do que as neutras e o duotone; as frias surgiram em dois dos exemplares. Nos casos em que a capa não exibe imagem, os elementos decorativos identificados consistem em moldura, fio e repetição/padrão.

Figura 12: Exemplo de capa portando imagem envolta em moldura. Fonte: Acervo pessoal.

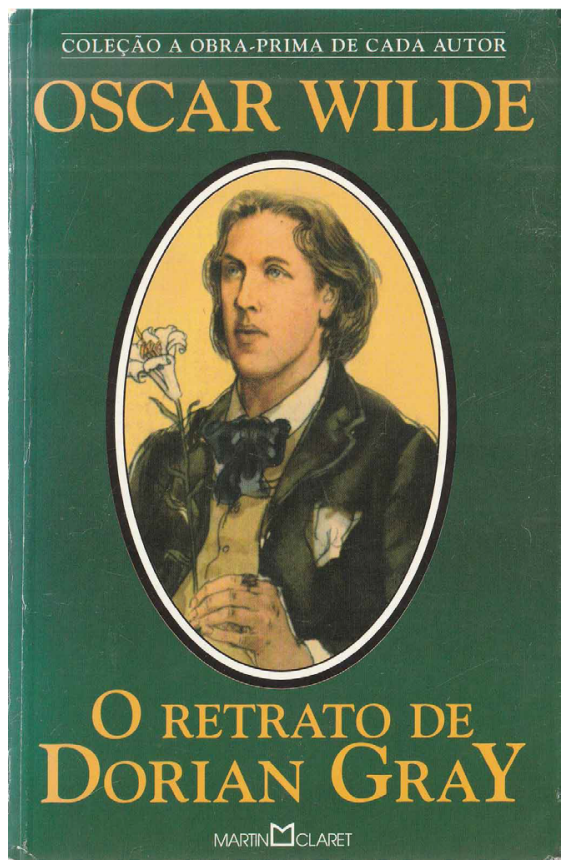




\section{Observações acerca das informações levantadas}

Tomando como ponto de partida as comparações, diferenciações e pontos em comum contidos na seção anterior, teceu-se certas considerações direcionadas aos materiais verificados. Nos componentes externos, o uso recorrente da lombada quadrada pode indicar uma alternativa para reduzir os custos de produção dos exemplares. A lateral nem sempre apresenta continuidade em relação às $1^{\mathrm{a}}$ e $4^{\mathrm{a}}$ capas, incorporando uma cor distinta em certos casos, porém a maior parte possui aplicação de cor de modo ininterrupto entre lombada, $1^{\mathrm{a}}$ e $4^{\mathrm{a}}$ capas. O exemplar de O Morro dos Ventos Uivantes de 2014 segue esse exemplo, porém com a presença de uma figura percorrendo capas e lateral. As únicas aplicações em relevo figuram na publicação de Noite na Taverna de 2002, recaindo sobre título da obra, moldura e nome do autor, e em O Morro dos Ventos Uivantes de 2014, acrescida da aplicação de verniz sobre o título da obra.

A segunda opção de encadernação utilizada, a capa dura, facilita o processo de leitura ao apresentar, em todos os casos, a aplicação da costura em sela. Aqui, os materiais utilizados para revestimento da capa detêm texturas diversas: um deles aparenta proximidade ao couro, observado na versão de Drácula lançada em 2002, enquanto outros possuem uma superfície lisa, caso que contempla os impressos de O Morro dos Ventos Uivantes datado de $1971 \mathrm{e}$ O Retrato de Dorian Gray de 1980. O exemplar de Noite na Taverna de 1973 porta a textura de modo mais evidente, uma vez que seu revestimento possui uma larga quantidade de rugas. O envoltório para o impresso de Dorian Gray de 2010 expõe um tecido cuja trama é bastante visível, enquanto o Drácula de 2014 se distancia dos demais, apresentando um acabamento fosco e com aplicação de verniz no título da obra. Percebe-se que a capa dura foi mais presente no primeiro recorte, perdendo espaço para a lombada quadrada no intervalo seguinte e voltando a aparecer em dois dos impressos do recorte mais recente.

Figura 13: Textura da capa de Noite na Taverna de 1973. Fonte: Acervo pessoal.

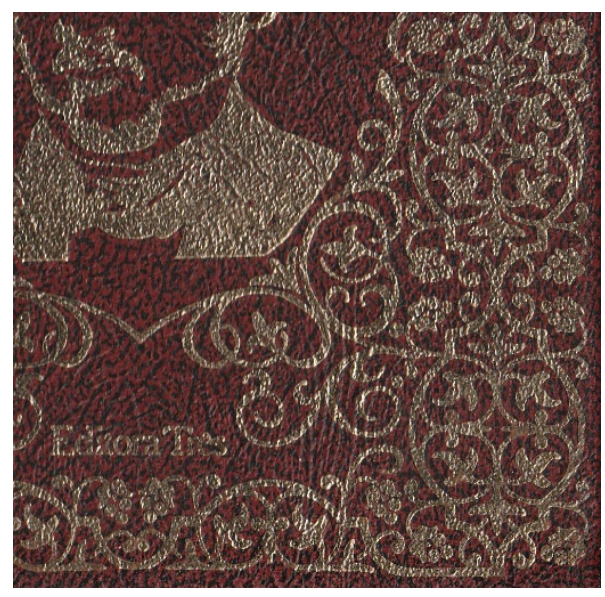

O hot stamping na cor dourada foi especialmente utilizado entre as publicações inseridas no recorte mais antigo, 1970 a 1989, exibido em 03 dos 05 livros, que, por sua vez, são as publicações que mais exibem arabescos e molduras, distribuídos entre $1^{\text {a }}$ capa e lombada. 
O recurso torna a aparecer em publicações do segundo recorte (1990 a 2009), porém com decorações mais contidas quando comparadas às observadas no intervalo anterior.

A recorrência da douração e dos arabescos nos livros do primeiro recorte pode estar vinculada à finalidade pertinente ao projeto gráfico dos impressos em questão, organizados em coleções que contemplam obras intituladas como clássicas da literatura. Conforme apontado por Nogueira (2018) em análise da coleção "Os Imortais da Literatura Universal", que inclui a edição de O Morro dos Ventos Uivantes de 1971 aqui estudada, as inscrições douradas em capa dura, visíveis na lombada dos volumes quando dispostos em uma estante, relacionam-se ao consumo dos livros para distinção do leitor. $O$ discurso presente em material publicitário de "Os Imortais" expõe a intenção de posicionamento da coleção enquanto um produto que ofereceria uma diferenciação simbólica, através de sua materialidade, para aquele que a possui. A douração parece ser uma tendência do período, conforme incidência de máquinas e equipamentos para uso da técnica presentes na seção "Guia de indústria gráfica", observada em Boletins da Indústria Gráfica (1970; 1971) publicados pela Associação Brasileira da Indústria Gráfica.

Figura 14: Peça publicitária da coleção "Os Imortais da Literatura Universal". O uso de adjetivos como "privilégio" e "monumental" exprimem características elegidas pela editora em referência ao saber e à construção gráfica adotada para os volumes. Fonte: Nogueira (2018).

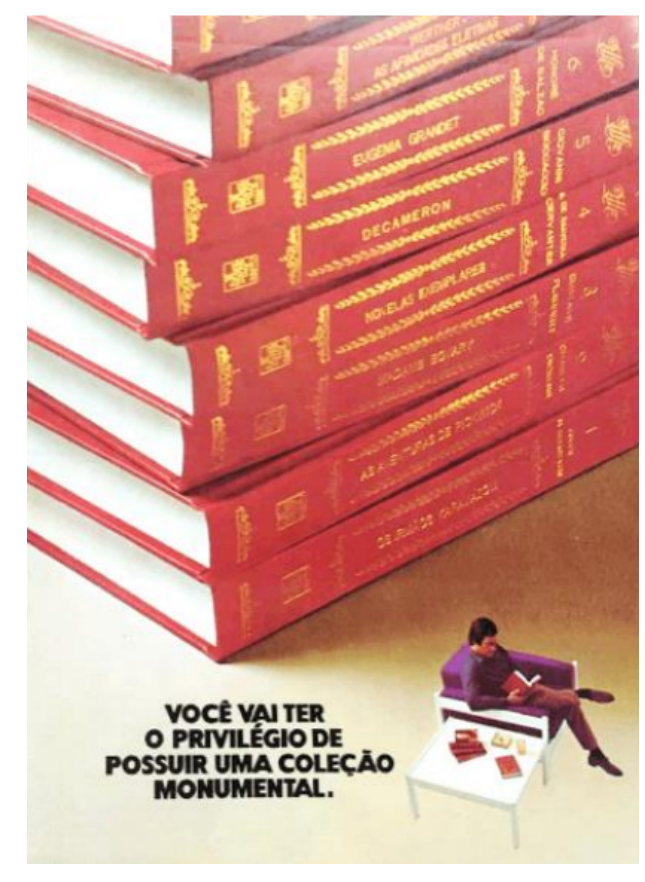

A relação entre os elementos pictóricos da capa e o texto foi clara na maior parte dos exemplares. Tem-se a figura do gato em Histórias Extraordinárias (2010), aludindo ao conto "O Gato Preto"; o castelo de torres altas em Drácula (2002 e 2014, sendo esse último combinado com a silhueta do conde); o pavão carregado pela capa de Dorian Gray (1980), fazendo um paralelo com a personalidade do protagonista, ou mesmo um retrato do(a) autor(a), como ocorre em Noite na Taverna (1971). 
Um fato sobressalente foi a inserção da maior parte dos livros coletados - 11 deles - em coleções, independentemente de editora; esse agrupamento se dá, especialmente, pela seleção de obras e autores tidos como clássicos, conforme citado anteriormente. Assim, além de conciliar os componentes do layout com o material textual, a diagramação desses impressos voltou-se a construir uma unidade sobre os títulos presentes no conjunto, mesmo que esses não pertençam ao mesmo gênero literário. Pontua-se, aqui, uma possibilidade de compreensão para a ideia de coleção trazida pelos exemplares enquanto um recurso que fornece ao livro, além da construção gráfica, "valores a ele atribuídos como símbolo social (...), que acionam certos dispositivos subjetivos e pessoais que levam à sua posse e coleção" (MURGUIA, 2009), entendendo que, através do arranjo dos objetos em conjunto, essa ideia de colecionismo compreende o objetivo do leitor em adquirir ou expor o livro, agregando um significado particular do sujeito àquele grupo de publicações.

Embora certos elementos utilizados na composição variem de exemplar para exemplar dentro da mesma coleção (como imagens, elementos de repetição, planos de fundo e cores), buscando estruturar uma identidade para cada obra, outros casos, como em O Morro dos Ventos Uivantes $(1971,1995)$ e Histórias Extraordinárias (1988) não recebem tratamento diferencial entre seus impressos, de modo que todos os títulos incluídos na coleção apresentam os mesmos elementos de capa. Nesse ponto, não foi possível atribuir características que identificassem as obras como pertencentes à literatura gótica.

Em contraposição, o Drácula de 2014 integra um box voltado ao "terror", de modo que as publicações exibem particularidades que dialogam com as características do sombrio tratadas pelo gótico, como o amplo uso de tons em preto e vermelho. Esse foi o único caso em que se observou certa aplicação de elementos visuais direcionados a uma possível "estética gótica". Pode-se reconhecer uma estrutura comum aos livros, como a preferência por tipos serifados no miolo, porém, a princípio, não há elementos que permitam a identificação da maior parte das obras como gótica.

Figura 15: Primeira capa, lombada e parte do miolo da edição de 2014 para Drácula. Fonte: Acervo pessoal.
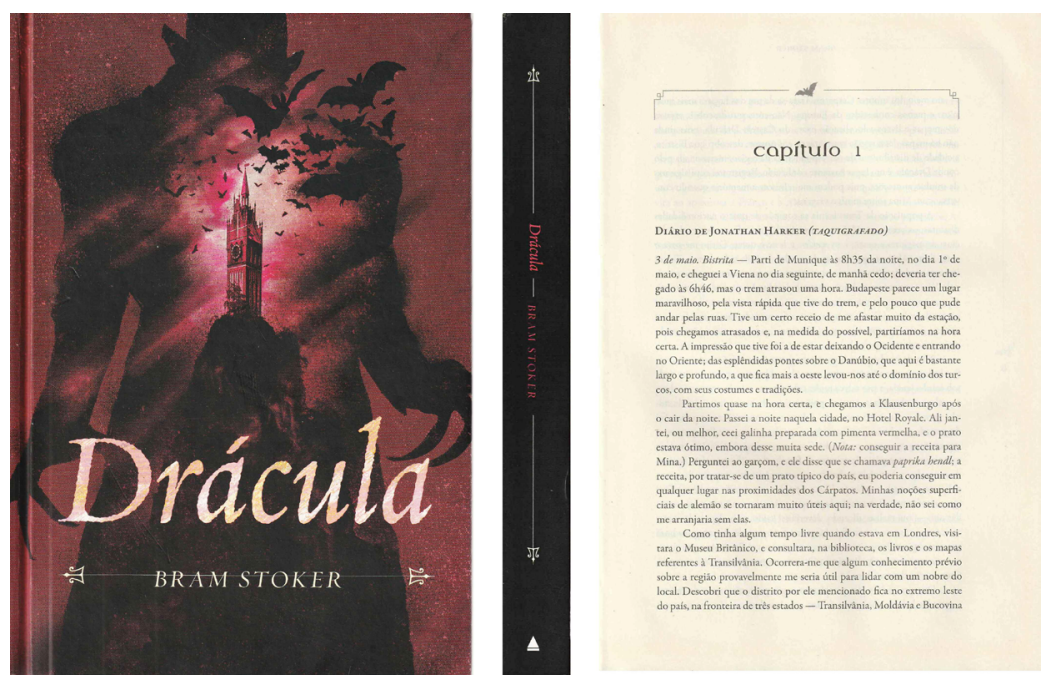
Ao tratar de cores na capa, em geral, as publicações expõem tonalidades variadas, como marrom, cinza, branco, verde e vermelho. Duas obras, em particular, detêm a mesma cor em tons distintos: vermelho em O Morro dos Ventos Uivantes, contemplando as versões de $1971 \mathrm{e}$ 1995, e verde para os impressos de O Retrato de Dorian Gray dos anos de 1999 e 2010. Na primeira ocasião, pela disposição de ambos os livros em coleções que possuem "layout padrão" para todos os livros da coleção, não se pode atribuir uma relação direta entre matiz e obra especificamente. A segunda situação, embora contenha materiais também organizados em coleções, é munida da atribuição de determinados componentes distintos nas edições (como cor e elementos de repetição), mas que ainda mantém a unidade entre o grupo. Dessa forma, o verde dentro do contexto do enredo, pode significar tanto o recomeço e a fertilidade (FRASER \& BANKS, 2007) quanto ciúmes e inveja (AMBROSE \& HARRIS, 2009).

Ironicamente, nenhum dos exemplares comporta, em qualquer fragmento textual, tipografia Gótica - ou Letras Negras, conforme classificação atribuída no checklist.

Por fim, verificou-se o fólio como o componente que recebeu mais mudanças em seu alinhamento. Enquanto todos os impressos do primeiro intervalo expunham o elemento no alinhamento inferior simétrico, o segundo recorte surge com uma mudança, colocando o fólio de quatro dos seus cinco exemplares na disposição inferior centralizada e apenas um como superior simétrico. Os livros mais recentes o detêm distribuído entre as variações inferior simétrica, superior simétrica e lateral centralizada.

\section{Considerações finais}

O trabalho aqui retratado objetivou analisar e expor componentes gráficos presentes em edições brasileiras de obras da literatura gótica por intermédio de um checklist. $O$ encaixe das publicações em intervalos permitiu a observação de elementos pertinentes a três períodos distintos, considerando permanências, variações e evoluções em relação à apresentação dos itens.

Evidenciando aspectos visuais, a pesquisa mostrou um pouco da trajetória percorrida pela composição visual das publicações nacionais através de seus componentes gráficos. $O$ ato de compreender os recursos empregados na editoração ao longo dos tempos torna possível o entendimento da aplicação de aspectos integrantes das edições atuais, transitando por adaptações e melhorias alcançadas pelo material. O propósito, nesse ponto, também inclui o caráter de memória ao emergir a "personalidade" dos impressos em distintos ciclos.

A investigação tornou viável a identificação de construções gráficas partilhadas pelas publicações; no entanto, a maior parte do material coletado não porta elementos que traduzem a "estética gótica" presente no texto. Apenas um dos exemplares, disposto em uma coleção voltada especificamente a títulos de "terror", contempla a estética de modo mais claro. A inclusão de onze dos quinze livros analisados em coleções, mesmo que de diferentes editoras, pode ser apontada como uma das questões colaboradoras em relação a esse quadro, 
de modo que a diagramação acaba por seguir a tendência de uma unidade presente em todos os livros inseridos no conjunto. Embora cores e elementos decorativos sofram alterações em certos casos, atribuindo certa distinção àquele exemplar diante da coletânea, não são artifícios reveladores do gênero literário das obras. Isso implica em certa ausência de conexão da representação gráfica com o conteúdo textual.

O propósito central de verificar e apontar componentes tipográficos, pictóricos e físicos encontra seus resultados na verificação dos dados obtidos a partir do objeto de estudo. A análise indicou pontos inicialmente não tencionados, como a baixa incidência de elementos pós-textuais, e também possibilitou o conhecimento de variações para certos componentes, como os tipos de lombada, além da adaptação de classificações mediante necessidades demandadas pelo material, exemplificada pelo fólio. A verificação, desde a composição do material para investigação até os resultados obtidos, proporcionou um entendimento mais preciso do funcionamento das variáveis elencadas e suas particularidades, mesmo que a relação entre texto e construção visual não tenha sido exposta de modo tão coeso. Por fim, ressalta-se, também, o desenvolvimento de uma ferramenta de análise gráfica - o checklist que pode vir a ser utilizada em outras pesquisas, bem como para propostas didáticas de ensino acadêmico relacionadas ao design editorial.

\section{Referências}

Ambrose, G. \& Harris, P. (2009b). Design básico: Cor. Porto Alegre: Bookman.

Ambrose, G. \& Harris, P. (2009a). Design básico: Grids. Porto Alegre: Bookman.

Ambrose, G \& Harris, P. (2012). Design básico: Layout ( $2^{\mathrm{a}}$ ed.). Porto Alegre: Bookman.

Ambrose, G \& Harris, P. (2011). Design básico: Tipografia. Porto Alegre: Bookman.

Barros, L. L. de, Araujo, J. L., \& Oliveira, E. A. de (2018). Memória Gráfica da Comunicação Impressa do Cariri. V Mostra UFCA, Juazeiro do Norte.

Boletim da Indústria Gráfica (BIG). Guia da indústria gráfica. São Paulo, v.6, n.22, 1970.

Boletim da Indústria Gráfica (BIG). Guia da indústria gráfica. São Paulo, v.5, n.23, 1971.

Carvalho, L. M. de. (2018). A Configuração Visual Gráfica de Cadernos Especiais do jornal O Povo sob o ponto de vista do Design de Notícias. Monografia, Universidade Federal do Cariri, Juazeiro do Norte, CE, Brasil.

Clair, K. \& Busic-Snyder, C. (2009). Manual de Tipografia: a história, a técnica, a arte (2a ed.). Porto Alegre: Bookman.

Dutra, T. L. M. \& Fonseca, L. P. (2014). Metodologia de análise gráfica do Jornal Posição: otimização de processos em pesquisas relacionadas à memória. Anais do Congresso Internacional de Design da Informação, 6, 1-5. http://dx.doi.org/10.5151/designpro-CIDI-175

Fonseca, J. da (2008). Tipografia \& design gráfico: design e produção gráfica de impressos e livros. Porto Alegre: Bookman.

Fraser, T. \& Banks, A. (2007). O guia completo da cor. São Paulo: Editora Senac. 
Haluch, A. (2013). Guia prático de design editorial: criando livros completos. Teresópolis: $2 A B$ Editora.

Joly, M. (2007). Introdução à Análise da Imagem (2a ed.). Lisboa: Edições 70.

Murguia, E. I. (2009) O colecionismo bibliográfico: uma abordagem do livro para além da informação. Encontros Bibli: Revista Eletrônica de Biblioteconomia e Ciência da Informação, n. esp. 1. sem., p. 87-104. DOI: 10.5007/1518-2924.2009v14nesp1p87.

Nogueira, W.A. À venda em todas as bancas: relação entre produção e circulação de livros colecionáveis comercializados pela Editora Abril na década de 1970. 2018. Tese (doutorado em Ciência da Informação). Escola de Comunicação e Artes, Universidade de São Paulo, São Paulo.

Primeiro Filme (2013). Enquadramentos: planos e ângulos. Recuperado em 28 out, 2019, de http://www.primeirofilme.com.br/site/o-livro/enquadramentos-planos-e-angulos.

Twyman, M. (1982). The graphic presentation of language. Information Design Journal, 3 (1), 2 - 22. Recuperado em 30 jun, 2019, de https://www.researchgate.net/publication/ 233582242_The_Graphic_Presentation_of_Language.

\section{Sobre o(a/s) autor(a/es)}

Letícia Lima de Barros, Mestranda, UFPE, Brasil <leticia.lima@ufpe.br>

Manoel Deisson Xenofonte Araújo, Mestre, UFCA, Brasil <deisson.araujo@ufca.edu.br> 